\title{
Energy Outlook in East Africa Region and the Carbon Emissions for Conventional Energy Projection (Part I)
}

\author{
Mwongereza Jean d'Amour'1, Aissa Boudjella1,2 \\ ${ }^{1}$ Pan African University Institute of Water and Energy Science (PAUWES), Tlemcen University, Tlemcen, Algeria \\ ${ }^{2}$ Bircham International University, Madrid, Spain \\ Email:jmwongereza@yahoo.fr, boudjellaa@hotmail.com
}

Received 4 May 2016; accepted 26 July 2016; published 29 July 2016

\begin{abstract}
In this investigation, we focus on the current energy sources and future projects situation in East Africa up to 2040. Electricity generation potential of energy mix and electrical capacity will be analyzed. For both electricity generation and electrical capacity, the data source shows that some forms of energies such bio-energy, solar PV, etc. will contribute less as well as with insignificant contribution of nuclear energy. Whereas hydro is dominating comparing with gas, oil, coal, solar PV, bio-energy and other renewables energies. From 2000 up to 2012, hydro and oil were only the one source of electricity generation. Starting from 2020, other forms of energies will appear and continue to increase at different rate. The international trade of electricity in this region will appear in 2020 and continue to increase as predicted by the data. Up to 2040, hydro will play a big role in electricity generation with other renewable energy sources, such as coal, oil, Gas, bioenergy and solar PV that will continue to increase at different rate. The share of solar PV in energy generation will slowly increase compared to other sources. The capacity of hydro and renewable energy sources will be high compared with other sources of energy such as bioenergy, coal, oil, PV solar, and gas. The results show also that bio-energy will increase slowly in electricity generation in comparison with other source of energies. The present report shows that oil will continue to emit a lot carbon dioxide compared to gas and coal. The emission of $\mathrm{CO}_{2}$ from total final consumption (TFC) of oil will continue to be high in comparing with $\mathrm{CO}_{2}$ emission from power generation (PG) of oil. But the emission of carbon dioxide from power generation of coal from 2025 until 2040 will be high compared with emission of $\mathrm{CO}_{2}$ generated from FTC of coal. In this period, the emission from TFC for gas will remain insignificant. The total final consumption emission of oil in general will dominate other emissions from both coal and gas. Due to this high emission of $\mathrm{CO}_{2}$, new technologies should be introduced in order to reduce gas pollution from TFC.
\end{abstract}

\section{Keywords}

Electricity Generation, Electrical Capacity, Renewable Energy, Carbon Dioxide Emissions 


\section{Introduction}

Africa is divided into blocks such as North Africa, Central African States, African States of East Africa, Southern Africa region, and West Africa. Most African population has no access to electricity and the inaccessibility will continue to increase as the population grows. Currently Africa has installed capacity of all energy mix (150 GW) which is comparable to what china installed in one or two years [1].

East Africa (EA) has a large number of populations without access to electricity. The fact is due to many reasons, such as no strong policies implantation in energy sector, lack of financial, and instability in security. However, some efforts were put in place in order to increase accessibility and affordability to the energy. Government, the private sector, civil society, family, must all play their part in preparing Africa's youth for a transforming continent.

According to IRENA report 2012, nearly 600 million people in Africa have no access to electricity [1]. This report was based on East Africa which accounts 11 countries such as Burundi, Djibouti, Egypt, Eritrea, Ethiopia, Kenya, Rwanda, Somalia, Sudan, Tanzania, and Uganda. In East Africa installed capacity in 2010 was more than 38GW with electricity generation of 160 TWh where the high portion of electricity was generated from gas-fired power plants. Egypt accounts $70 \%$ of installed capacity in the region [1]. Ethiopia, Kenya and Uganda are among the most populous countries in East Africa, and have the biggest number of population either with no access to electricity [2]. The international electricity trade in this region is still low. Except, countries like Burundi and Rwanda shared electricity trade consumption from Republic Democratic of Congo (RDC). Some projects are in place using interconnection between these countries which will help the energy accessibility to the population. The electricity generation in this region is based on gas, hydro and oil-fired power plants with small contribution of wind and solar. As the projection shows, hydro will continue to contribute a lot compared to other forms of energy. The carbon dioxide emission from power generation using of gas and oil cannot be not controlled due to high dependency on them.

Over the past years, renewable energy policies and a clear understanding of energy performance have been developed to differentiate success from failure and to identify what must be avoided to improve this performance. The main goal in this investigation is to become familiar with the theories of energies and policies that make possible this performance. To set the path towards this goal, we going to take a first look at energy growth, and learn why these energy phenomena merit intention.

The purpose of this article is to analyze the data of energy generation, electricity capacity and carbon emission obtained from the conventional energy in East Africa region [3].

\section{Methodology}

This work will focus on current electricity generation situation and future projection in East Africa region. The data obtained from International Energy Agency report of 2014 is analyzed, including electricity generation, electricity capacity and carbon emissions [3]. The future projection of how these forms of energy will be used up to 2040 is examined and discussed. Some projects which will help people to have access and improve their living standards. The scenario of improving installed capacity by introducing friendly environmentally renewable energy sources has been elaborated and compared with fossil fuels.

\section{Electricity Generation and Electrical Capacity in East Africa Region}

The map shows the big challenges East Africa and Africa in general has in energy access for the population where a big number has no access to electricity and this affect the development of our countries because energy plays a lot in development of countries (Figure 1). In this section, some Eastern countries were assessed such Egypt, Kenya, Tanzania, Rwanda, Uganda and Ethiopia. The Egypt accounts $70 \%$ of the region installed capacity and the other hand small counties like Burundi, Djibouti and Rwanda, whose individual installed capacity is less than $0.5 \%$ of the regional total capacities.

\subsection{Egypt}

Egypt is classified as a country of lower middle income. Egypt is the 25th largest oil producer in the world and the 16th in natural gas production. It is the largest Non-Organization of the petroleum exporting countries (OPEC) oil producer and comes second behind Algeria in producing natural gas. Natural gas is the dominant 


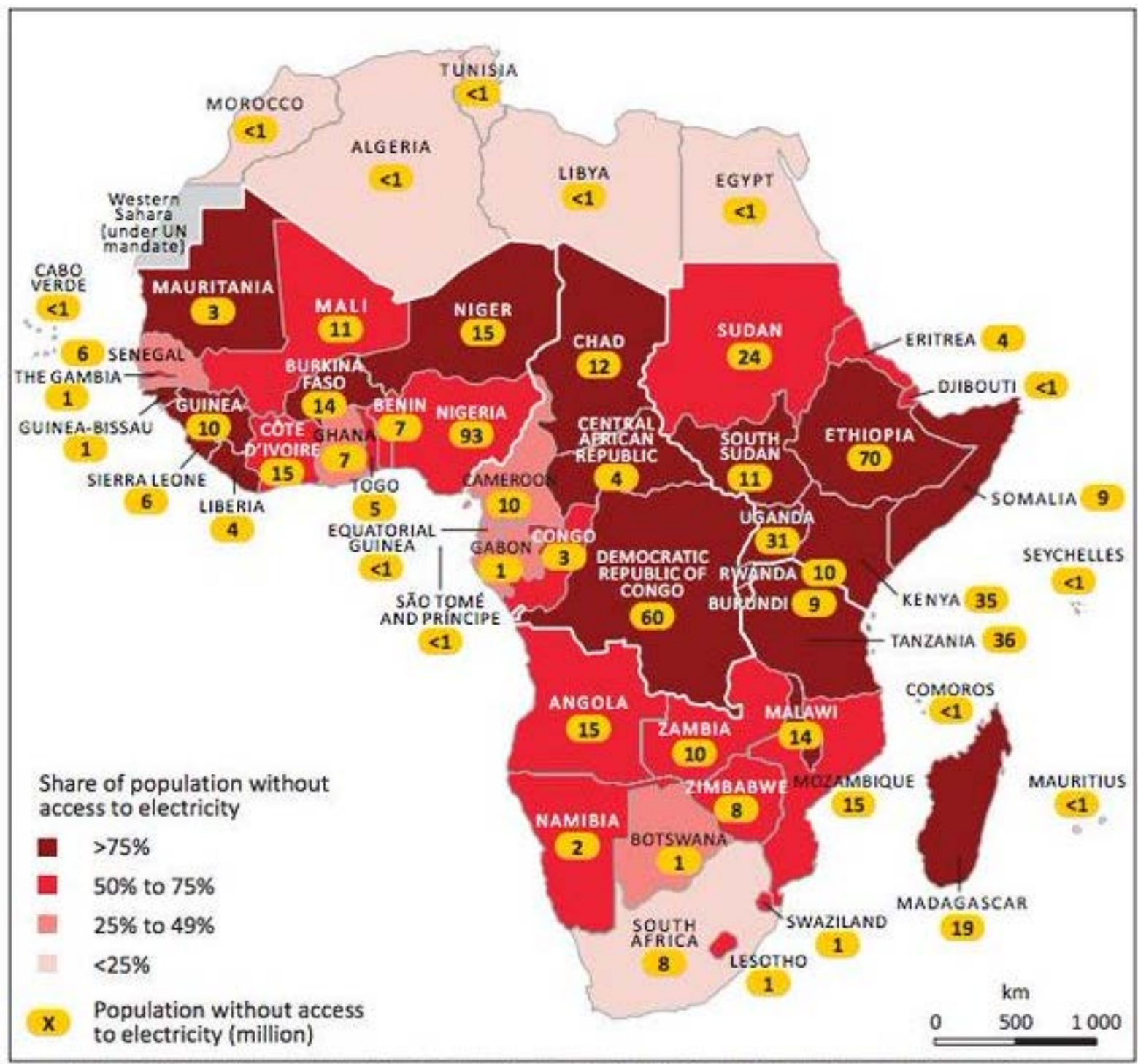

Figure 1. Number and share of people without access to electricity by country 2012 [3].

fuel in the process of power generation with hydro power comes as the biggest representative of renewables. May 2015, Egypt's generating capacity was 31.45 GW, slightly higher than the expected peak demand in 2015 of $30 \mathrm{GW}$ [4]. The average electrification rate in Egypt between the rural areas and the urban areas was 99.1\%. January 2015, Egypt had 4.4 bbl of oil reserves [5].

\subsection{Kenya}

The overall access to electricity in Kenya is $15 \%$ and only $42 \%$ of the urban people in Kenya have access to electricity while $87 \%$ of the people in Rural Kenya rely on Kerosene for lighting [6]. Kenya has a huge energy potential including geothermal, bio-energy, solar, wind, hydro, oil and coal. In 2014, the installed capacity of Kenya was 1773 MW and is expected to grow to 19,200 MW by 2030 [7]. The contributors of electricity generated from hydro are $51.1 \%$, fossil fuels $26.6 \%$, geothermal $14 \%$, gas turbines $3.4 \%$, cogeneration $1.7 \%$, and $0.3 \%$ wind power [6].

\subsection{Tanzania}

Tanzania as other countries in East Africa still faces a challenge of access to electricity with annual electricity 
demand growing at a rate of $10 \%$ to $15 \%$ and only $24 \%$ of Tanzania population has access to electricity. Tanzania's annual per-capita energy consumption is about $133 \mathrm{KWh}$, which is very low compared to world average of $2500 \mathrm{KWh}$ [8]. The high portion of energy generation is coming from hydro. In addition, Tanzania has discovered gas which contributes to energy generation. Tanzania has hydro power project with Rwanda and Burundi with 90 MW for each country.

\subsection{Rwanda}

Rwanda has by far one of the lowest per capita electricity consumption in the world; Rwanda consumes about $42 \mathrm{kWh} /$ year/capita compared with $478 \mathrm{kWh}$ in sub-Saharan Africa and $1200 \mathrm{kWh}$ for developing countries as whole [9]. Rwanda energy mix is dominated by biomass that accounts about $85 \%$ of primary energy use, $11 \%$ of petroleum and $4 \%$ for electricity. Currently power supply of 155 MW which represents $23 \%$ of energy is generated from grid interconnection [10]. The current electricity generation by energy mix represents: $49 \%$ hydro, 24\% thermal, $2 \%$ methane, $5 \%$ solar, $1 \%$ off grid hydro, $9 \%$ off grid thermal, and $10 \%$ imports [11].

According to African Development Bank Group, Energy Sector Review and Action plan 2013, Rwanda had target to increase electricity generation up 1160 MW by 2017 where the installed capacity was comprise: 300 MW of hydropower, 310 MW of geothermal power, 300 MW of methane-based power, $200 \mathrm{MW}$ of peat-based power, $200 \mathrm{MW}$ of diesel thermal plants. The plan has required an investment cost of $\$ 500$ million/year. Due to different circumstance, this target was changed to $563 \mathrm{MW}$ in 2017. Others projects shared with Congo and Burundi like Rusizi III (48 MW) and Rusizi IV (98 MW) with costs of \$150 million and \$240 million, respectively [9].

\subsection{Uganda}

Only about $18.2 \%$ of the total population has access to electricity. In 2013, the energy demand of Uganda was at $136 \mathrm{TWh}$ with per capita energy demand of $4050 \mathrm{kwh} /$ person per year. Meanwhile the generation mix stood at 845.735 MW, of which 696.4 MW were from hydro, 119.835 MW from thermal, and 29.5 MW from cogeneration sources [12]. The resources are considerably unexploited yet have great electric potentials with geothermal estimated at 450 MW, biomass; 1650 MW, hydro; over 2000 MW, and solar energy; 200 MW [13].

\subsection{Ethiopia}

Ethiopia as other countries almost $85 \%$ of the population has not electric access. Most of Ethiopia's energy supply is covered by waste and biomass (92\%), oil (6.7\%) and hydropower (0.9\%) [14]. However, many projects have been successful constructed to meet high electricity demand such Tekeze (hydroelectric: $300 \mathrm{MW}$ ), Tana Beles (hydroelectric: 460 MW), Gibe II (hydroelectric: 420 MW), Amerti Nesha (hydroelectric: 98 MW), Ashegoda (Wind: $30 \mathrm{MW}$ ) and Adama I (Wind: $51 \mathrm{MW}$ ).

According to the Ministry of Water, irrigation and energy (MoWIE) in 2015 said that the country has a generation capacity of $2310 \mathrm{MW}$ and Ethiopian Electric Power has a plan of expanding the nation's power output capacity to 15,000 MW by the end of second Growth and Transformation plan which stretches from July 2015 to 2020.

\section{East Africa New Scenario}

\subsection{Electricity Generation and Electrical Capacity}

According to East Africa New Scenario from Energy Outlook [3], the summarized data of electricity generation and trade with electrical capacity projection were summarized below in Table 1, Table 2 and was discussed in the following section.

\subsection{Carbon Dioxide Emissions}

Some countries have gas and oil which most are used to produce electricity. Countries such Egypt, Ethiopia, Rwanda, Somalia, Sudan, Tanzania and Uganda have gas. Tanzania produces coal. Electricity generation through gas-fired power plants and oil-fired power plants dominates which leads to high carbon emissions. Emissions come from burning coal and gas. Transport also contributes in carbon emissions due to high use of 
Table 1. Electricity generation and trade (TWh). Source: Africa energy outlook 2014 [3].

\begin{tabular}{cccccccc}
\hline & 2000 & 2012 & 2020 & 2025 & 2030 & 2035 & 2040 \\
\hline Coal & & & 3 & 9 & 16 & 22 & 29 \\
Oil & 4 & 8 & 8 & 10 & 12 & 16 & 22 \\
Gas nuclear & & & 3 & 7 & 9 & 14 & 22 \\
Hydro & 6 & 19 & 32 & 44 & 58 & 73 & 90 \\
Bioenergy & 0 & 0 & 2 & 4 & 6 & 8 & 10 \\
Solar Pv & 0 & 0 & 0 & 1 & 3 & 4 & 7 \\
Other renewables & 0 & 2 & 8 & 13 & 22 & 34 & 50 \\
Net imports & 0 & 0 & -1 & -5 & -7 & -9 & -11 \\
Total generation & 10 & 29 & 56 & 93 & 133 & 180 & 241 \\
\hline
\end{tabular}

Table 2. Electrical capacity (GW). Source: Africa energy outlook 2014 [3].

\begin{tabular}{|c|c|c|c|c|c|c|}
\hline & 2012 & 2020 & 2025 & 2030 & 2035 & 2040 \\
\hline Coal & & 1 & 2 & 4 & 5 & 7 \\
\hline Oil & 4 & 5 & 5 & 6 & 7 & 7 \\
\hline Gas & 0 & 1 & 2 & 3 & 4 & 6 \\
\hline \multicolumn{7}{|l|}{ Nuclear } \\
\hline Hydro & 4 & 7 & 10 & 13 & 17 & 20 \\
\hline Bioenergy & & 0 & 1 & 1 & 1 & 2 \\
\hline Solar pv & & 0 & 1 & 2 & 3 & 4 \\
\hline Other renewables & 0 & 2 & 3 & 4 & 6 & 9 \\
\hline Total capacity & 8 & 16 & 24 & 63 & 33 & 55 \\
\hline
\end{tabular}

diesel. Table 3 summarizes the projection contribution of carbon emissions from both power generation and total final consumption of coal, oil and gas.

\section{Results and Discussion}

This section presents and analyses the results of the data from Africa Energy Outlook report 2014 [3]. The report shows the contribution of different forms of energies and forecast them up to 2040. It summarizes the power generation, electrical capacity and emissions of carbon dioxide from power generation and total energy consumption from different sectors.

As indicated in the graph (Figure 2) electricity capacity will continue to increase at different rate whereby hydro will play a big role comparing with other forms of energies. In contrast, the contribution of nuclear capacity could remain insignificant as indicated in graph (Figure 2). From 2012 up 2035, energy capacity generated from hydro and oil will continue to be high. The results show also that up to 2040 hydro and other renewable energy sources keep their capacity high compared with others energy sources. Bioenergy will increase slowly in electricity generation with respect to other source of energies. In 2012, gas, coal, bio-energy, solar PV, and other renewables their contributions were insignificantly compare to oil and hydro.

Figure 3 shows electricity generation and trade trend characteristics generated from different resources from 
Table 3. Emissions of $\mathrm{CO}_{2}$ from power generation (PG) and total final consumption (TFC) in (Mt). Source: Africa energy outlook 2014 [3].

\begin{tabular}{|c|c|c|c|c|c|c|c|}
\hline & 2000 & 2012 & 2020 & 2025 & 2030 & 2035 & 2040 \\
\hline Total $\mathrm{CO}_{2}$ & 19 & 40 & 59 & 79 & 101 & 128 & 161 \\
\hline Coal & 0 & 2 & 8 & 16 & 25 & 34 & 45 \\
\hline Oil & 19 & 38 & 50 & 61 & 73 & 89 & 109 \\
\hline Gas & 0 & 0 & 1 & 2 & 3 & 5 & 7 \\
\hline Total power generation & 4 & 6 & 10 & 19 & 28 & 40 & 53 \\
\hline Coal (PG) & - & - & 3 & 10 & 17 & 23 & 30 \\
\hline Oil (PG) & 4 & 6 & 6 & 7 & 9 & 12 & 19 \\
\hline Gas (PG) & - & - & 1 & 3 & 5 & 8 & 14 \\
\hline Total final consumption & 14 & 33 & 49 & 60 & 73 & 89 & 108 \\
\hline Coal (TFC) & 0 & 2 & 5 & 8 & 11 & 16 & 24 \\
\hline Oil (TFC) & 14 & 31 & 46 & 59 & 76 & 101 & 132 \\
\hline Gas (TFC) & $\mathbf{0}$ & 0 & 0 & 0 & 0 & 0 & 0 \\
\hline
\end{tabular}

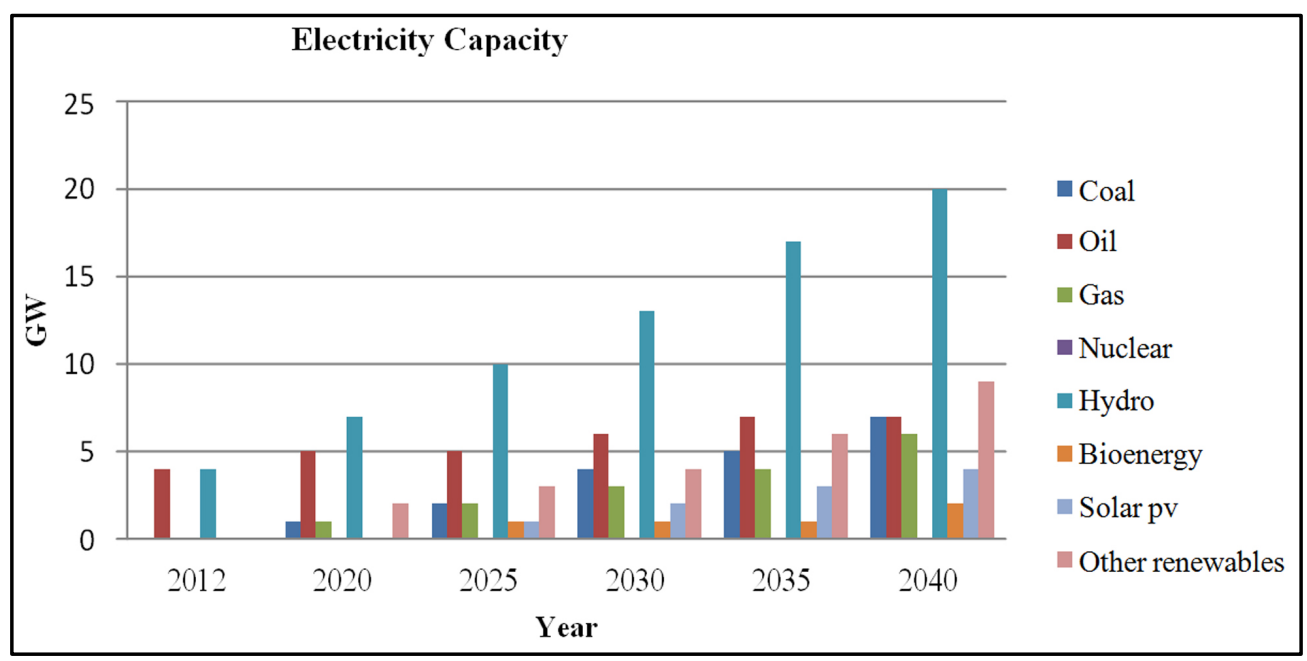

Figure 2. Electrical capacity from 2012 to 2040 Source: Africa energy outlook 2014 [3].

2020 up to 2040. The energy model shows that hydro, coal, oil, gas, bio-energy and solar PV will continue to increase at different rate between 2012 and 2040: 5.7\% of hydro, 3.6\% of oil, 13\% of bio-energy, 31.6\% of solar PV. The exportation will appear in 2020. Some countries will meet their national demand and export some electricity. Hydro with high rate will play a big role in electricity generation. From 2000 up 2012, electricity was generated using only hydro and oil. Starting from 2020, other forms of energies will appear and continue to increase at different rate as indicated in graph (Figure 3). The contribution of nuclear in energy generation will not contribute significantly. The share of solar PV in energy generation will increase slowly compared to other sources.

Figure 4(a) shows that oil and coal will continue to emit high carbon dioxide in the atmosphere comparing to gas and this due to different reasons where transport will continue to rely on oil and coal will play a big role in electricity generation. This also means that some countries will continue to discover oil and coal; other will continue to import those resources. The emission from gas will appear in 2020 and continue to increase significantly. The comparison in graph (Figure 4(b)) shows the same where oil is dominating in percentage of carbon dioxide shared emissions in 2012 and 2040.The percentage of emissions of gas and coal will in-crease in 2040 while for oil will slowly reduced. 


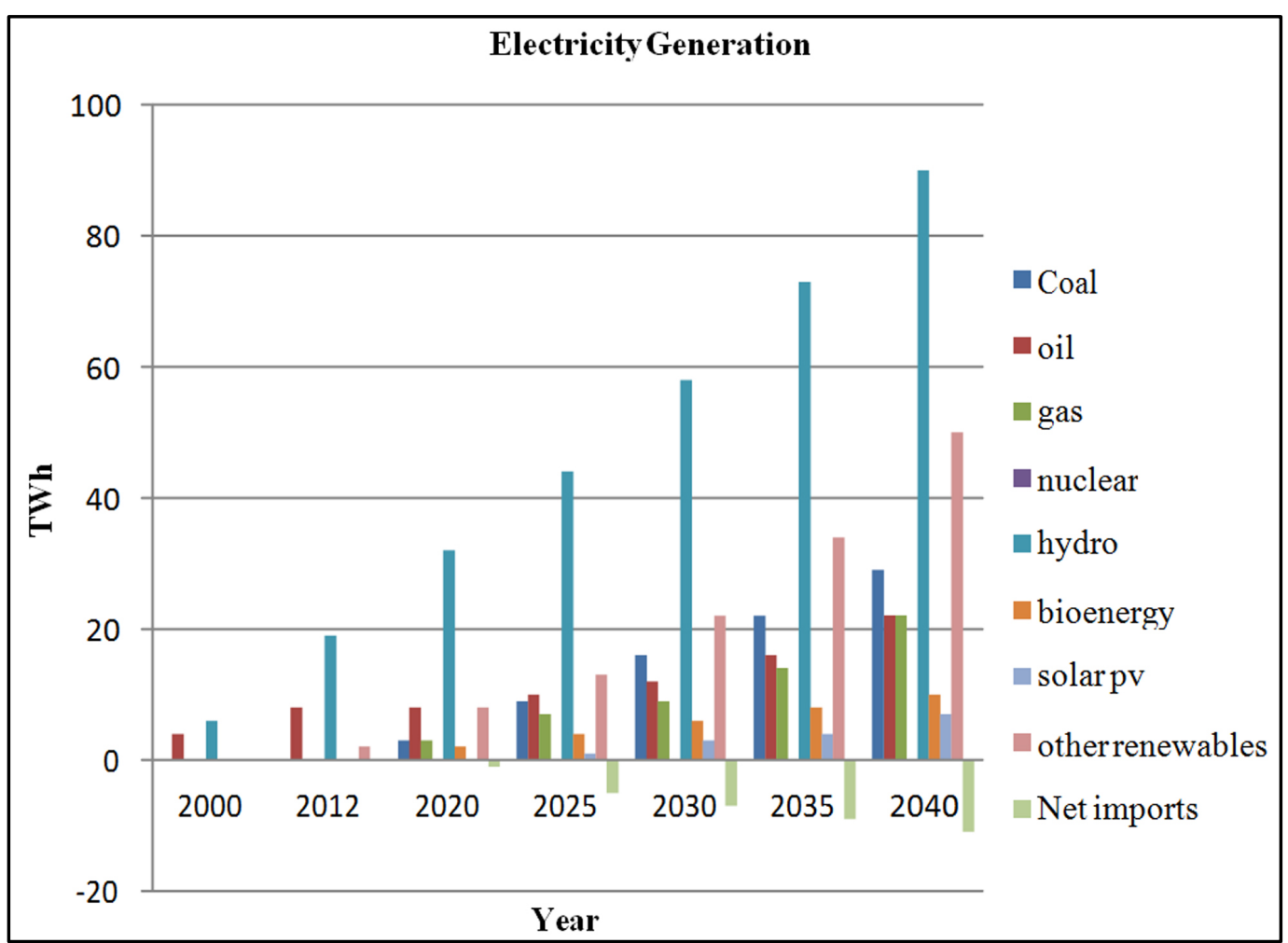

Figure 3. Electricity generation from 2012 to 2040 Source: Africa energy outlook 2014 [3].

Figure 5(a) illustrates the emission of $\mathrm{CO}_{2}$ from the total final consumption (TFC) of oil and power generation (PG) of oil. The results show that TFC has high rate of $\mathrm{CO}_{2}$ emissions compared with PG. On the other hand, from 2025 until 2040, emission of carbon dioxide from power generation of coal will be high comparing with emission of $\mathrm{CO}_{2}$ generated from coal FTC. The emission from TFC for gas will continue to be insignificant. Whereas, the total final consumption emission of oil in general will dominate other emissions from both coal and gas.

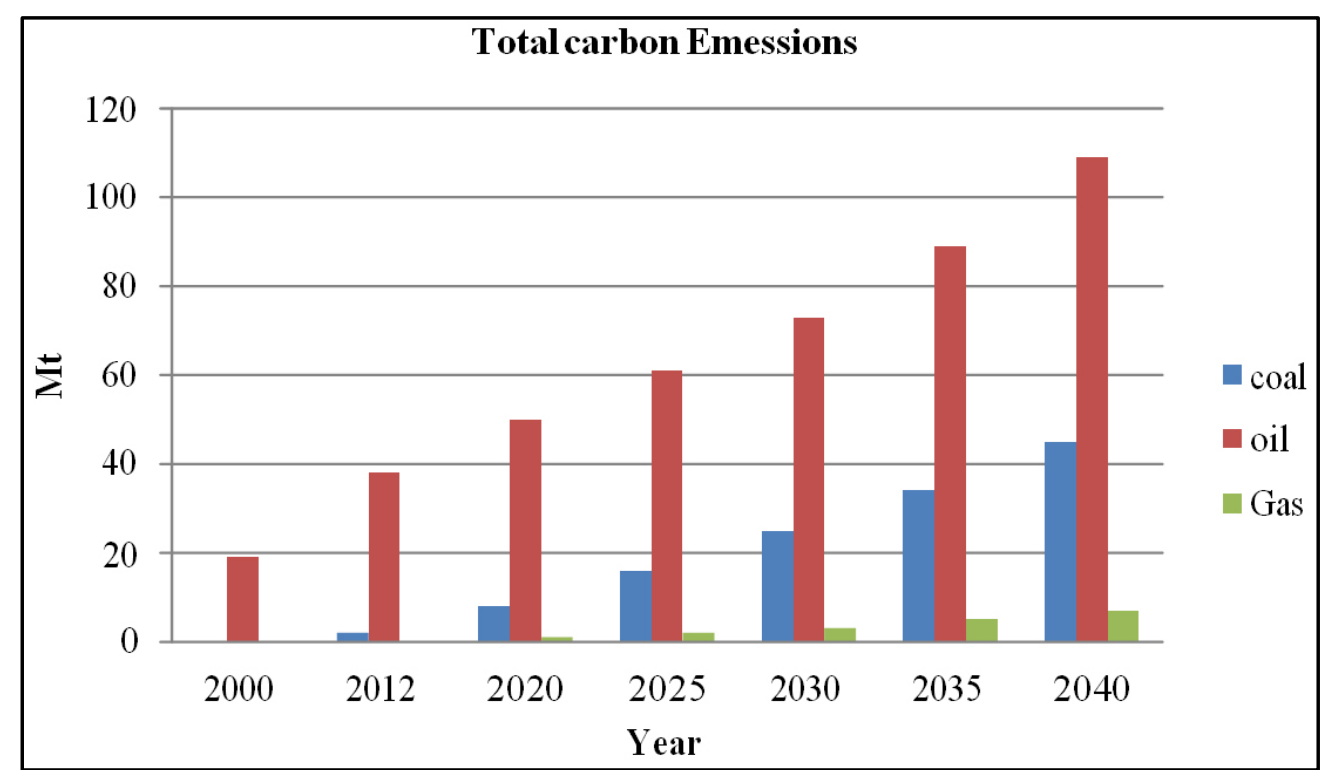

(a) 


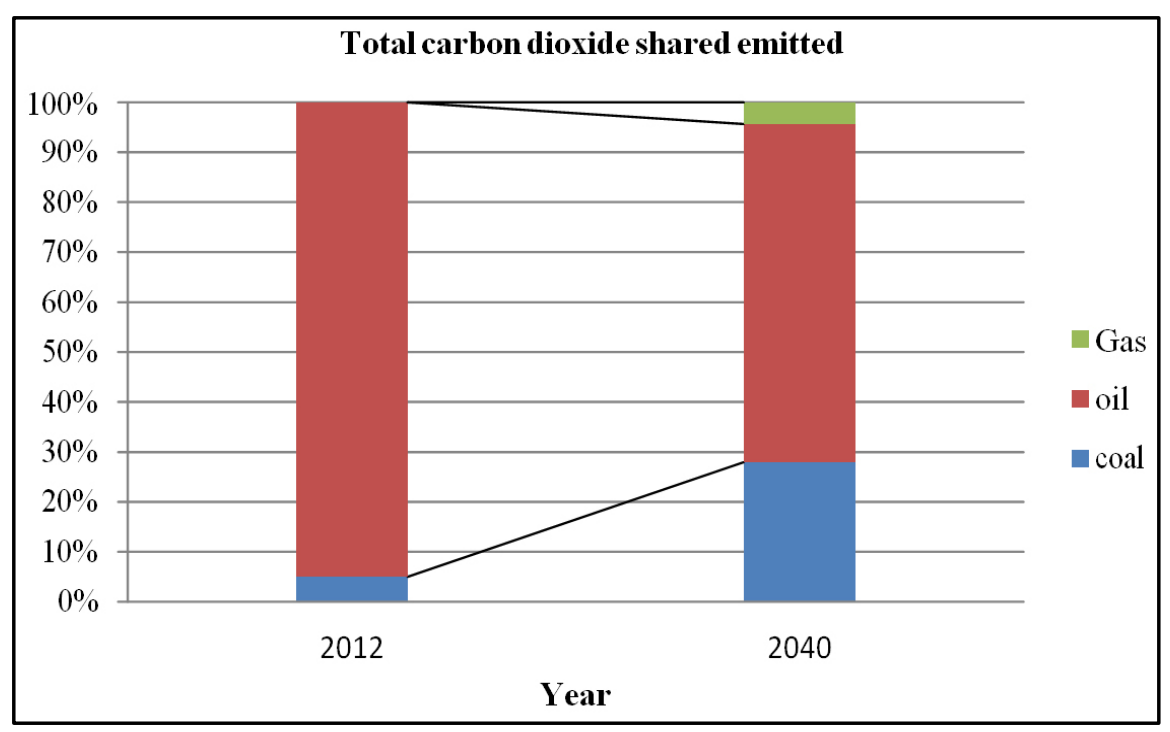

(b)

Figure 4. (a) Combined carbon dioxide shared emissions from 2000 to 2040. Source: Africa Energy Outlook 2014 [3]. (b) Comparison between 2012 and 2040 of total carbon dioxide shared. Source: Africa Energy Outlook 2014 [3].

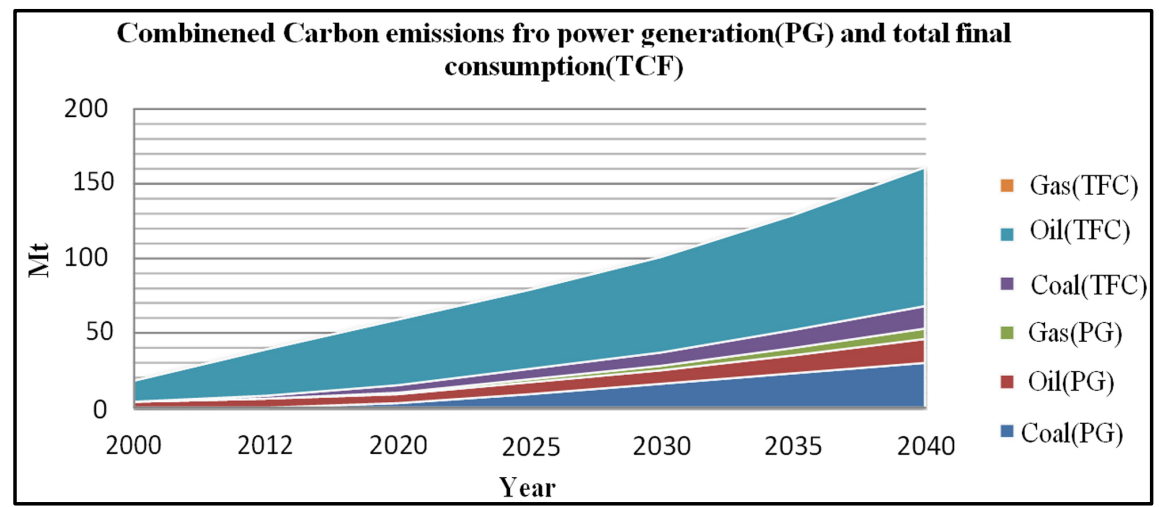

(a)

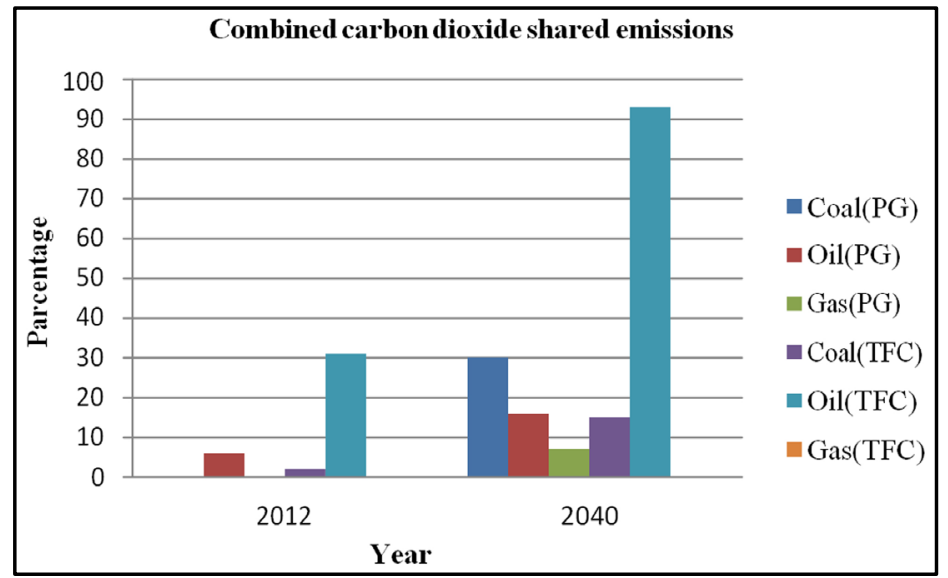

(b)

Figure 5. (a) Combined Carbon emissions from power generation (PG) and total final consumption (TFC) of East Africa from 2012 to 2040. Source: Africa Energy Outlook 2014 [3]. (b) Comparison between 2012 and 2040 combined carbon dioxide shared. Source: Africa Energy Outlook 2014 [3]. 
Figure 5(b) shows the percentage of combined carbon dioxide emissions of 2012 and 2040. In 2012 the emissions from power generation and total final consumption of gas and also emission from power generation of coal were insignificantly. In 2040 the emission from total final consumption of gas will be insignificantly. The emissions from power generation of oil, coal, gas lead to increase of electricity generation in 2040.

\section{Conclusions}

East Africa counts the majority number of population without electricity accessibility, affordability, and reliable energy. Many countries still rely on biomass which leads to land degradation, waste time for women and children looking for fire wood. This is situation with lack of energy accessibility, generates incurable illness from breathe smoking during cooking. Due to different reasons such as poverty, insecurity, lack of strong policies, the existing different forms of energy potential (like water, solar irradiation, geothermal, gas, and wind) in East Africa are not exploited to meet the demand.

Both electricity generation and electricity capacity produced from the contribution of hydro will continue to dominate other forms of energies. For electricity generation the energy model predicts that the exportation of energy will increase. In general bio-energy will contribute less in both electricity generation and electricity capacity comparing with other forms of energies.

For conventional energy, the emission of carbon dioxide from oil will continue to dominate other conventional energy such as gas and coal. Emission from total final consumption of oil will dominate emissions from other conventional energies. As result, in order to reduce carbon dioxide emissions, more technologies should be introduced. For example, Renewable energies should be the first introduced to reduce carbon dioxide emissions. Bio-energy has to be motivated for substitute diesel used especially in transport to mitigate the emissions for the purpose of environmental protection.

Reinforcement of energy trade based on grid interconnection should be prioritized to balance energy supply with energy demand.

Energy policies should be well prepared as well as implemented to meet local, regional and international measures. The international energy organizations should help this region and Africa in general to overcome this energy challenges for the purpose of eliminating poverty through promoting and reinforcing energy sector. Government, the private sector, civil society and most fundamentally, the family, must all play their part in preparing Africa's youth for a transforming continent.

\section{References}

[1] International Renewable Energy Agency-IRENA (2012) Prospects for the African Power Sector. Abu Dhabi.

[2] International Renewable Energy Agency-IRENA (2015) Africa Power Sector, Planning and Prospects for Renewable, Synthesis Report.

[3] International Energy Agency-IEA (2014) Africa Energy Outlook, A focus on Energy Prospects in Sub-Sahara Africa, World Energy Outlook Special Report.

[4] Middle East Economic Survey-MEES (2015) Egypt Adds Power Ship to Short-Term Plan, Lines up Loans for EEHC. Volume 58, Issue 19.

[5] Oil \& Gas Journal (2015) Worldwide Look at Reserves and Production.

[6] Government of Kenya-GOK (2014) Ministry of Energy and Petroleum, Updated Least Cost Power Development Plan Study Period 2013-2031.

[7] Mbithi, J. (2014) Off Solar Case Study and Opportunities in Kenya. Ministry of Energy and Petroleum, Nairobi.

[8] Kitonga, J.F. (2015) The Tanzania Energy Sector under the Universal Principles of the energy charter. The European Union, Brussels.

[9] AfDB (2013) Rwanda Energy Sector Review and Action Plan. African Development Bank Group, Tunis.

[10] AfBIN (2015) Rwanda Commits to 70\% Electricity Access by 2018. African's Business Investment News. http://biznisafrica.co.za/rwanda-commits-to-70-electricity-access-by-2018/

[11] Republic of Rwanda, The second annual United Nations (2015) Sustainable Energy for all Action Agenda. http://www.se4allforum.org/presentation/

[12] MEMD (2014) 2013 Statistical Abstract. Sector planning/Policy Analyst Unit, Ministry of Energy and Mineral Devel- 
opment (MEMD), Kampala.

[13] REA (2007) Renewable Energy Policy for Uganda. Rural Electrification Agency (REA), Kampala.

[14] Md. Minarul Islam, E.M. (2013) Development of Alternative Scenario for Ethiopia’s Electricity Sector by LEAP Software. Global Journal of Researches in Engineering Electrical and Electronics Engineering.

\section{Submit or recommend next manuscript to SCIRP and we will provide best service for you:}

Accepting pre-submission inquiries through Email, Facebook, LinkedIn, Twitter, etc.

A wide selection of journals (inclusive of 9 subjects, more than 200 journals)

Providing 24-hour high-quality service

User-friendly online submission system

Fair and swift peer-review system

Efficient typesetting and proofreading procedure

Display of the result of downloads and visits, as well as the number of cited articles

Maximum dissemination of your research work

Submit your manuscript at: http://papersubmission.scirp.org/ 